\title{
Indications, Clinical Outcomes, and Survival Rate of Pediatric Penetrating Keratoplasty in Suburban Malaysia: A 10-year Experience
}

\author{
Lam Mun-Wei ${ }^{1}$, Haslinda Md Said ${ }^{1}$, Rajendran Punitan ${ }^{1}$, Mohtar Ibrahim ${ }^{1}$, Ismail Shatriah ${ }^{1}$ \\ 1. Ophthalmology, School of Medical Sciences, Universiti Sains Malaysia, Kubang Kerian, MYS
}

Corresponding author: Ismail Shatriah, shatriah@usm.my

\section{Abstract}

\section{Purpose}

To describe the demographics, indications, clinical outcomes and survival rate of penetrating keratoplasty in Malaysian children living in a suburban area, and discuss the literature on paediatric penetrating keratoplasty.

\section{Methodology}

A retrospective review of medical records was performed on children younger than 17 years of age who had undergone penetrating keratoplasty in Hospital Universiti Sains Malaysia from January 2008 to December 2017. We recorded demographic data, presenting visual acuity, indications, final visual acuity, and graft survival at 12 months into the postoperative period.

\section{Results}

Sixteen eyes of 14 children had penetrating keratoplasty. Mean age was $7.8 \pm 5.9$ years. Both genders were equally affected. The main indications were infective keratitis (56.25\%), congenital corneal opacity (18.75\%) and trauma (12.50\%). There were $62.50 \%$ of patients who had a preoperative visual acuity worse than $6 / 60$. Fifty percent had other combined procedures during the surgery, including lens aspiration, peripheral iridectomy, pupilloplasty and glaucoma tube implant. Best corrected visual acuity of $6 / 12$ or better was achieved in $18.75 \%$ of patients. A hazy graft was noted in $68.75 \%$ of patients, and was attributed to graft rejection, glaucoma and graft failure. There was a statistically significant association between the presence of vascularized cornea, intraocular inflammation and combined surgery with survival rate of the graft at one-year postoperative period $(\mathrm{p}<0.05)$.

\section{Conclusions}

Infective keratitis is the main indication for penetrating keratoplasty in our pediatric patients. Good visual outcome was documented in a small percentage of the patients. Amblyopia and hazy graft were the main barriers to success in this group of patients. Vascularized cornea, inflammation and combined surgery had

Received 11/20/2018

Review began 11/27/2018 Review ended 12/12/2018 Published 12/17/2018

\section{() Copyright 2018}

Mun-Wei et al. This is an open access article distributed under the terms of the Creative Commons Attribution License CC-BY 3.0., which permits unrestricted use, distribution, and reproduction in any medium, provided the original author and source are credited. significantly affected the survival rate of the grafts in our series.

Categories: Ophthalmology, Pediatrics

Keywords: clinical outcome, pediatric penetrating keratoplasty, suburban malaysia, graft survival rate

\section{Introduction}

Pediatric keratoplasty is a challenging surgical procedure. Indications for pediatric keratoplasty differ between developing and developed countries. Trauma and infection are the most common causes of pediatric keratoplasty in developing countries [1-4]. However, keratoconus and congenital corneal opacities are the main reasons for pediatric keratoplasty in developed countries [5-10].

Available data on pediatric keratoplasty in Asian countries are limited. Published reports are mainly from India and China $[1-2,11]$. Recently, Low et al. described the primary outcome of pediatric keratoplasty in Singapore [10]. We aim to describe demographic data, indications and clinical outcomes of pediatric keratoplasty in Malaysia, and discuss the published literatures from both developing and developed countries.

\section{Materials And Methods}

A retrospective review was performed on 14 children younger than 17 years who underwent penetrating keratoplasty surgery in Hospital Universiti Sains Malaysia, Malaysia from January 2008 to December 2017. The patients were monitored for a minimum of three years period (range 36 to 96 months). This study was conducted according to the Declaration of Helsinki. 
Hospital Universiti Sains Malaysia is a tertiary hospital on the east coast of Peninsular Malaysia. It serves as a referral centre and is equipped with cornea and pediatric ophthalmology subspecialty services. It receives referrals from the east coast states of Peninsular Malaysia, i.e. Kelantan, Terengganu and Pahang which cover an area of approximately $63,974 \mathrm{~km}^{2}$ with a population of 4.6 million people in 2018 .

Patients less than 17 years of age who had undergone penetrating keratoplasty were included in our case review. All patients were co-managed by the cornea and pediatric ophthalmology consultants, during preand postoperative visits. Penetrating keratoplasty was performed by a single corneal surgeon. The glaucoma tube implant was done by a glaucoma consultant.

We recorded the patients' age during the initial presentation, gender, visual acuity before the procedure, indications, and period from diagnosis to the surgery. Other combined surgical procedures during the penetrating keratoplasty, culture and histopathological analysis of the recipient cornea, visual acuity at one year after the surgery, graft survival, and causes of poor final visual acuity were also reviewed and documented. Data was analysed using the Statistical Package for Social Sciences (SPSS) version 22 (IBM, Armonk, NY).

\section{Results}

Sixteen penetrating keratoplasty procedures were performed in Hospital Universiti Sains Malaysia during the 10 -year period. They were from 16 eyes of 14 children; one patient had procedures done in both eyes for congenital cornea opacity, while another patient undergone re-graft. The ages during the penetrating keratoplasty procedures ranged from 1 to 16 years (mean: $7.8 \pm 5.9$ years).

Nine eyes (56.25\%) were operated on when the patients were less than five years of age, while six eyes (37.50\%) had surgery when the patients were between 11 and 16 years. No gender predilection was observed. Right and left eyes were equally affected. Infective keratitis was documented in nine eyes (56.25\%), followed by congenital corneal opacity in two eyes (12.50\%), and trauma in two eyes (12.50\%). These are presented in Table 1. 


\section{Cureus}

Characteristics

No. (\%)

Age range (years)

$0-5$

6-10

11-17

6 (37.50)

Gender ${ }^{\mathrm{a}}$

Male

Female

Laterality

Right eye

$8(50.00)$

Left eye

Indication for penetrating keratoplasty

Acquired traumatic

Traumatic corneal scar

Acquired non-traumatic

Perforated bacterial keratitis

Scarred bacterial keratitis

$1(6.25)$

Herpetic keratitis

2 (12.50)

Interstitial keratitis

Corneal opacity secondary to Steven Johnson

Re-graft

$1(6.25)$

Congenital

Congenital cornea opacity

Bullous keratopathy secondary to congenital glaucoma

\section{TABLE 1: Demographic characteristics and clinical diagnosis.}

a Calculated based on 14 patients.

Ten eyes (62.50\%) had visual acuity worse than $6 / 60$ before the penetrating keratoplasty procedure, while six eyes (37.50\%) were unable to be examined. No eyes displayed a visual acuity better than $6 / 60$ before the procedure. Eight eyes $(50.00 \%)$ had other combined procedures during the penetrating keratoplasty surgery. These procedures included lens aspiration (four eyes, $25.00 \%$ ), peripheral iridectomy (two eyes, $12.50 \%$ ), pupilloplasty and glaucoma tube implant (one eye, $6.25 \%$ for both). Nine eyes (56.25\%) were operated on within one year of the initial consultation and diagnosis while the remaining patients took longer than a year due to poor socioeconomic status, refusal for surgery during the early phase and being unfit for general anesthesia when listed for surgery. The above information is summarized in Table 2. 


\section{Cureus}

Characteristics

Visual acuity before procedure

6/12 and better

$6 / 15-6 / 60$

Worse than $6 / 60$

$10(62.50)$

Not able to examine

$6(37.50)$

Postoperative visual acuity at one year

6/12 and better

$6 / 15-6 / 60$

Worse than $6 / 60$

$6(37.50)$

Unable to determine

$6(37.50)$

Surgical procedure with penetrating keratoplasty

Penetrating keratoplasty only

Combined with other procedures

Lens aspiration

Peripheral iridectomy

Pupilloplasty

Molteno tube implant

Time from diagnosis to penetrating keratoplasty procedure

Two weeks

Six months

One year

Two years

$4(25.00)$

Three years

More than three years

TABLE 2: Clinical and surgical characteristics.

We encountered great difficulty in obtaining samples for culture in infective cases. Four eyes (25.00\%) were proven to be culture negative. Histopathological analyses revealed evidence of acute inflammation, acute suppurative keratitis, corneal scars, fibrosis and vascularization in four eyes (one eye per condition, $6.25 \%$ ). The remaining results were unavailable.

Three eyes (18.75\%) had a final visual acuity better than 6/12 at one year after the procedure. One eye (6.25\%) achieved a best corrected visual acuity of 6/15 only due to amblyopia. Final visual acuities worse than $6 / 60$ were documented in six eyes (37.50\%), while visual acuities were not able to be assessed in the remaining six eyes (37.50\%). Out of 12 eyes with poor final visual acuity, hazy grafts were noted in 11 eyes (68.75\%). These were due to graft rejections in seven eyes (43.75\%) which mostly contributed by infective cases, glaucoma in three eyes (18.75\%), and a graft failure in one eye (6.25\%). The relevant data are presented in Table 3. 


\section{Cureus}

Characteristics

Clear graft

Hazy graft

Postoperative rejection

Postoperative glaucoma

Graft failure
No. (\%)

5 (31.25)

7 (43.75)

3 (18.75)

1 (6.25)

TABLE 3: Survival of the graft at one year.

The Kaplan-Meier survival rates showed significant association between the risk factors such as vascularized cornea $(p=0.026)$, intraocular inflammation $(p=0.022)$ and simultaneous surgery $(p=0.007)$ with the survival of corneal graft (Figure 1). Factors like previous surgery performed, glaucoma, iridocorneal touch, re-graft and age were analyzed but showed no significant association with the outcome of corneal graft survival rate. 


\section{Cureus}
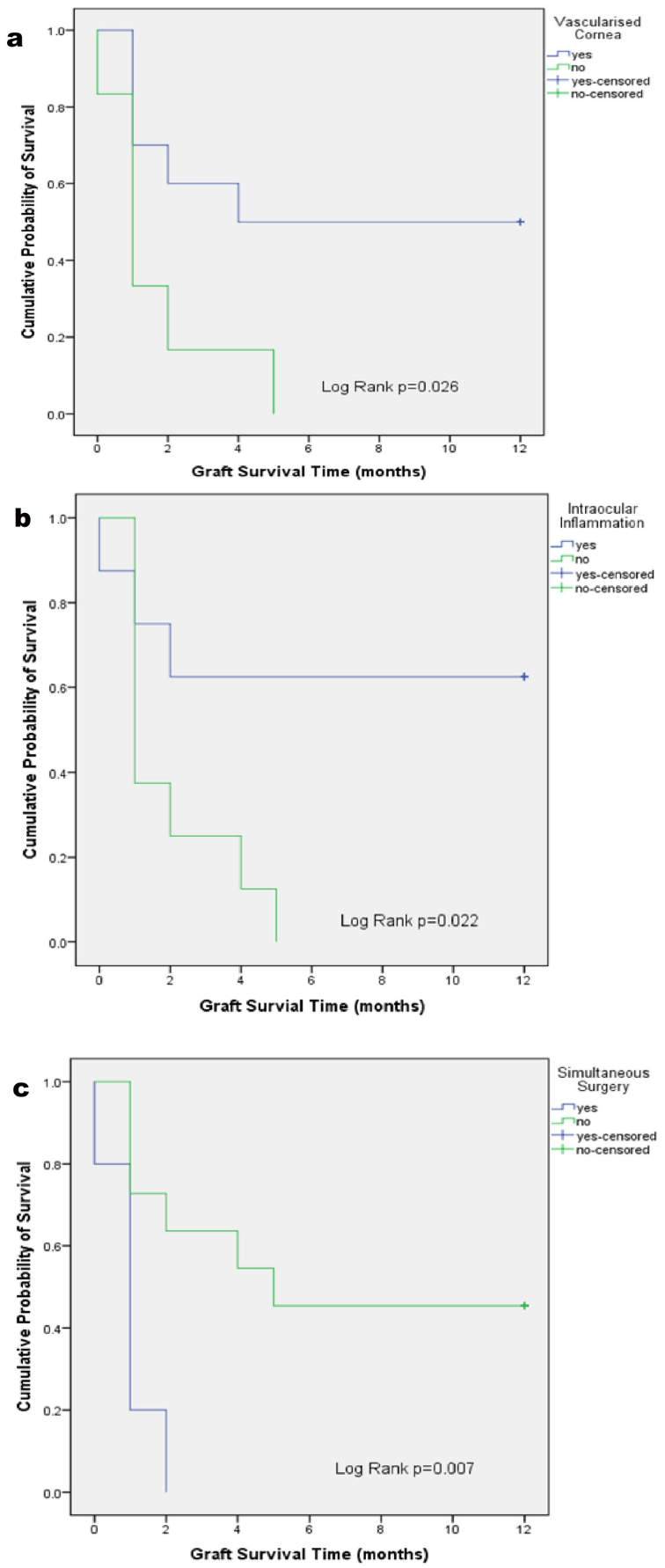

FIGURE 1: The Kaplan-Meier graft survival for (a) grafts with vascularized cornea, (b) grafts with intraocular inflammation and (c) grafts undergoing simultaneous surgery.

\section{Discussion}

The majority of pediatric keratoplasty reviews have described penetrating keratoplasty as the main procedure involved [1-11]. Other procedures, such as anterior lamella keratoplasty and Descemet-stripping automated endothelial keratoplasty have also been described in a few reports [2,5,10-13]. Table 4

summarizes published studies on pediatric keratoplasty from China, United States, New Zealand, Singapore, India, Finland, Denmark, Tunisia, Saudi Arabia, Australia and our present study [2,4-5,10-16]. 


\section{Cureus}

\begin{tabular}{|c|c|c|c|c|c|c|c|c|c|}
\hline & & [11] & & & [15] & & [16] & [14] & [13] \\
\hline Country/Year & Malaysia/2018 & India/2015 & China/2007 & Singapore/2014 & Saudi Arabia/2007 & Zealand/2005 & Australia/2003 & Tunisia/2011 & Denmark/2013 \\
\hline Number of eyes & 16 & 66 & 410 & 44 & 165 & 58 & 19 & 16 & 65 \\
\hline Number of patients & 14 & 66 & 371 & 44 & 134 & 52 & 16 & 15 & 60 \\
\hline Range (years) & $1-17$ & 2 months -12 & 2.5 months- 14 & 1 month-15 & 5 months -12 & 2 weeks-14 & 2 weeks-15 & 3 months-14 & $<16$ \\
\hline Mean age (years) & 7.8 & 4.0 & 7.8 & 8.4 & $N A$ & 10.6 & 9.2 & 11.2 & NA \\
\hline Gender & $M=F 7: 7$ & $M>F 43: 23$ & $M>F 259: 112$ & $M>\mp 67: 38$ & NA & $M>F 34: 18$ & $M>F 10: 6$ & $M>F 10: 5$ & NA \\
\hline \multicolumn{10}{|l|}{ Indication for Graft, n (\%) } \\
\hline 1. Congenital & $3(18.75)$ & $24(36.36)$ & $112(27.32)$ & $18(40.90)$ & $130(78.79)$ & $9(15.52)$ & $8(42.11)$ & $2(12.5)$ & $3(4.62)$ \\
\hline CHED & $\mathrm{NA}$ & $6(9.09)$ & NA & $1(2.27)$ & $35(21.21)$ & NA & $1(5.26)$ & $\mathrm{NA}$ & NA \\
\hline Non-CHED & NA & $6(9.09)$ & $\mathrm{NA}$ & $\mathrm{NA}$ & $\mathrm{NA}$ & $\mathrm{NA}$ & NA & NA & NA \\
\hline Anterior segment dysgenesis & $\mathrm{NA}$ & $6(9.09)$ & $\mathrm{NA}$ & $15(34.09)$ & $28(16.9 \%)$ & $4(6.90)$ & $3(15.79)$ & NA & NA \\
\hline Aniridia & $\mathrm{NA}$ & NA & NA & NA & NA & $2(3.45)$ & $2(10.53)$ & $\mathrm{NA}$ & $2(3.08)$ \\
\hline MPS Type 1 & NA & NA & NA & NA & NA & NA & $1(5.26)$ & NA & NA \\
\hline Cornea dystrophy & NA & NA & $29(7.07)$ & $\mathrm{NA}$ & NA & NA & NA & $1(6.25)$ & NA \\
\hline Cornea opacity & $2(12.50)$ & $6(9.09)$ & $53(12.93)$ & NA & NA & $2(3.45)$ & $1(5.26)$ & $1(6.25)$ & NA \\
\hline Congenital glaucoma & $1(6.25)$ & NA & $\mathrm{NA}$ & $1(2.27)$ & $49(29.70)$ & $\mathrm{NA}$ & $\mathrm{NA}$ & $\mathrm{NA}$ & $\mathrm{NA}$ \\
\hline Limbal dermoid & NA & NA & $30(7.32)$ & $1(2.27)$ & $6(3.64)$ & $1(1.72)$ & NA & NA & NA \\
\hline Others & NA & NA & NA & NA & $12(7.27)$ & NA & NA & NA & $1(1.54)$ \\
\hline $\begin{array}{l}\text { 2. Acquired non-traumatic, } \mathrm{n} \\
(\%)\end{array}$ & $11(68.75)$ & $37(56.06)$ & $148(36.10)$ & $26(59.10)$ & $18(10.91)$ & $43(74.14)$ & $11(57.89)$ & $8(50.00)$ & $54(83.08)$ \\
\hline Keratoconus & NA & NA & $37(9.02)$ & $10(22.73)$ & NA & $39(67.24)$ & $8(42.11)$ & $5(31.25)$ & 12 (18.46) \\
\hline Infectious keratitis & $9(56.25)$ & $22(33.33)$ & $93(22.68)$ & $4(9.09)$ & $18(10.91)$ & $4(6.90)$ & $1(5.26)$ & $3(18.75)$ & $20(30.77)$ \\
\hline Cornea perforation & NA & NA & NA & $2(4.55)$ & NA & NA & NA & NA & NA \\
\hline Steven Johnson Syndrome & $1(6.25)$ & NA & NA & NA & NA & NA & NA & $\mathrm{NA}$ & $\mathrm{NA}$ \\
\hline Adherent leukoma & NA & NA & NA & NA & NA & NA & $1(5.26)$ & NA & NA \\
\hline Keratomalacia & $\mathrm{NA}$ & $11(16.67)$ & $7(1.71)$ & $\mathrm{NA}$ & $\mathrm{NA}$ & $\mathrm{NA}$ & $\mathrm{NA}$ & NA & NA \\
\hline Regraft & $1(6.25)$ & $4(6.06)$ & NA & $\mathrm{NA}$ & $\mathrm{NA}$ & NA & $1(5.26)$ & $\mathrm{NA}$ & $12(18.46)$ \\
\hline Bullous keratopathy & NA & NA & NA & $1(2.27)$ & NA & NA & NA & NA & NA \\
\hline Cornea scar & NA & NA & NA & $8(18.18)$ & NA & NA & NA & NA & NA \\
\hline Iris tumor & $\mathrm{NA}$ & NA & NA & $1(2.27)$ & NA & NA & NA & NA & NA \\
\hline Unknown & $\mathrm{NA}$ & NA & $11(2.68)$ & NA & NA & NA & NA & NA & $6(9.23)$ \\
\hline Others & NA & NA & NA & NA & NA & NA & NA & NA & $4(6.15)$ \\
\hline 3. Acquired traumatic & $2(12.5)$ & $5(7.58)$ & $150(36.6)$ & $0(0.00)$ & $17(10.30)$ & $6(10.34)$ & NA & $6(37.50)$ & $8(12.31)$ \\
\hline \multicolumn{10}{|l|}{ Visual acuity at one year, $\mathrm{n}(\%)$} \\
\hline $6 / 12$ or better & $3(18.75)$ & NA & $\mathrm{NA}$ & $\mathrm{NA}$ & $8(4.80)$ & $18(35.29)$ & $7(36.8)$ & $2(12.50)$ & NA \\
\hline $6 / 15$ to $6 / 60$ & $1(6.25)$ & NA & NA & NA & $52(31.51)$ & $16(32.00)$ & $3(15.8)$ & $6(37.50)$ & NA \\
\hline
\end{tabular}




\section{Cureus}

\begin{tabular}{|c|c|c|c|c|c|c|c|c|c|}
\hline Worse than $6 / 60$ & $6(37.5)$ & NA & NA & NA & 105 (63.63) & $12(25.32)$ & $9(47.4)$ & $8(50.00)$ & NA \\
\hline Not able to examine & $6(37.5)$ & NA & NA & NA & NA & $5(9.80)$ & NA & NA & NA \\
\hline \multicolumn{10}{|c|}{$\begin{array}{l}\text { Graft survival at one year, } \mathrm{n} \\
\text { (\%) }\end{array}$} \\
\hline Clear graft & $5(31.75)$ & NA & NA & (92.80) & $73(44.24)$ & $42(82.00)$ & $14(73.68)$ & $8(52.00)$ & $38(60.00)$ \\
\hline Graft rejection & $7(47.35)$ & NA & NA & NA & NA & NA & $1(5.26)$ & $4(24.00)$ & NA \\
\hline Glaucoma & $3(18.75)$ & NA & NA & NA & NA & NA & NA & NA & NA \\
\hline Graft failure & $1(6.25)$ & NA & NA & NA & $92(55.75)$ & $8(16.00)$ & $3(15.70)$ & NA & $25(40.00)$ \\
\hline Secondary trauma & NA & NA & NA & NA & NA & NA & 1 (5.26) & $3(19.00)$ & NA \\
\hline Inflammation & NA & NA & NA & NA & NA & NA & NA & $1(5.00)$ & NA \\
\hline Died & NA & NA & NA & NA & NA & $1(5.00)$ & NA & NA & NA \\
\hline
\end{tabular}

TABLE 4: Published data on pediatric keratoplasty from 2003 till 2018.

CHED: Congenital hereditary endothelial dystrophy; MPS: Mucopolysaccharidosis; NA: Not available.

The mean age in our study is consistent with a report by Shi et al., in 2007 who conducted a large retrospective study in North China ( $7.8 \pm 4.3$ years) [2]. Low et al. reported mean age of $8.4 \pm 5.63$ years in their review [10]. In contrast, a relatively younger age group was observed by Kusumesh and Vanathi, from India [11]. The mean age reported from developed countries, ranging from 9.2 to 12 years, is slightly older than those reported from developing countries [5,12-16].

We found no gender predilection in our present cases of pediatric keratoplasty. Similar observations have also been reported by Huang et al. and Dana et al., where both genders were equally affected $[4,17]$. On the other hand, a majority of the literature from Asia, North Africa, Australia and the United States have observed that boys outnumbered girls in their studies on pediatric keratoplasty $[2,10-11,14,16,18]$.

The indication of penetrating keratoplasty is broadly classified into congenital, acquired non-traumatic, and acquired traumatic corneal opacities. Our results showed that the most common indication was infective keratitis (56.25\%), which belongs to the acquired non-traumatic group. Infective keratitis has been reported to be the leading cause in India (33.33\%) and Denmark (30.77\%) [11,13]. Keratoconus is the most common indication of pediatric keratoplasty in New Zealand (67.26\%) and Australia (42.11\%) [5,16]. Congenital corneal opacity is the main indication in the United States (61.60\%), Singapore (40.90\%) and Saudi Arabia $(78.79 \%)[4,10,15]$.

Corneal lacerations due to trauma (12.50\%) were the second highest in our series. Trauma was reported as the most common cause of pediatric keratoplasty in North China (36.60\%), Finland (25.0\%) and Tunisia (37.5\%) $[2,12,14]$. Majander et al. mentioned that they had a higher percentage of keratoplasty indicated for traumatic corneal scars, which were performed to facilitate other intraocular surgeries. On the other hand, no penetrating keratoplasty secondary to corneal trauma was reported from Singapore and Australia $[10,16]$.

Our series documented a final visual acuity of $6 / 12$ or better in only $18.75 \%$ (three eyes). This data is consistent with a report by Limaiem et al., who reported that $12.20 \%$ of their patients had satisfactory final visual acuity, and ocular trauma contributed to $37.50 \%$ in their study [14]. On the contrary, Patel et al. and McClellan et al. observed more encouraging visual acuity results in their reports (35.29\%, 36.8\% respectively) $[5,16]$. Most of their patients had undergone penetrating keratoplasty due to keratoconus, which carries a better prognosis.

Al-Ghamdi et al. from Saudi Arabia reported that more than half of their patients achieved a final visual acuity worse than $6 / 60$, and they attributed this finding to a majority of their patients having congenital corneal opacities [15]. Congenital corneal abnormalities are difficult to manage as they are usually associated with concurrent ocular diseases and amblyopia, which lead to poor visual outcomes [15,17]. However, there was no data available on final visual acuities from North China, the United States, Singapore, India, Finland and Denmark $[2,4,10-13]$.

Our study demonstrated that only $31.25 \%$ (five eyes) of the patients had clear grafts after one year following 
the procedure. Other published reports documented higher percentage of patients with clear graft (range from 52 to $90 \%$ ) $[4,5,13-14,16]$. Hazy cornea observed in the majority of our patients was due to postoperative rejections (43.75\%), persistent glaucoma (18.75\%), and graft failure (6.25\%). Refusal and poor compliance to amblyopia treatment were also identified in our patients. On the other hand, a lower percentage of postoperative rejections was observed in Tunisia (24.0\%) and Australia (5.26\%) [14,16]. Graft failure was noted in the reports by Patel et al. (16.0\%), Hovlykke et al. (40.0\%), Al-Ghamdi et al. (55.75\%), and McCellan et al. (15.6\%). However, graft clarity was not mentioned in the studies performed in North China, India and Finland [2,11-12].

All our patients who had combined procedures (eight eyes) developed poor final visual acuity. Our observation is consistent with other authors who reported poor graft survivals in cases with combined surgical procedures $[5,9,10,19,20]$. Kusumesh et al. reported that two of their eight graft rejections occurred in cases where penetrating keratoplasty was performed as a combined procedure [11]. Patel et al. and Low et al. concurred that combined intraoperative procedures are a risk factor for graft failure $[5,10]$. Likewise, AlGhamdi et al. observed that combined glaucoma (graft survival 28\%) and cataract (graft survival 19.2\%) surgeries reduce the rate of graft survival [15]. Several risk factors are known to affect long-term corneal graft survival. In our study, vascularized corneal, simultaneous surgery and intraocular inflammation affected graft survival rate (Figure 1). These risk factors were consistent with other reported studies $[5,10,12,13]$. Other factors that were known to affect graft survival rates such as previous surgery performed, glaucoma, re-graft and iridocorneal touch were not significantly associated with our graft survival rates. This is possibly due to the limited small sample size collected in our retrospective study.

\section{Conclusions}

Infective keratitis is the main indication for pediatric keratoplasty in our series. Both genders were equally affected. Less than one-third of the patients had clear grafts. A majority had poor visual acuity due to amblyopia and hazy grafts that resulted from graft rejections, persistent glaucoma, and graft failures. Our findings support the existing data regarding paediatric keratoplasty from developing countries. More workup and efforts are necessary to improve the diagnosis, treatment, and postoperative care for children who require keratoplasty from developing countries.

\section{Additional Information \\ Disclosures}

Human subjects: All authors have confirmed that this study did not involve human participants or tissue. Animal subjects: All authors have confirmed that this study did not involve animal subjects or tissue. Conflicts of interest: In compliance with the ICMJE uniform disclosure form, all authors declare the following: Payment/services info: All authors have declared that no financial support was received from any organization for the submitted work. Financial relationships: All authors have declared that they have no financial relationships at present or within the previous three years with any organizations that might have an interest in the submitted work. Other relationships: All authors have declared that there are no other relationships or activities that could appear to have influenced the submitted work.

\section{References}

1. Sharma N, Prakash G, Titiyal JS, Tandon R, Vajpayee RB: Pediatric keratoplasty in India: indications and outcomes. Cornea. 2007, 26:810-813. 10.1097/ICO.0b013e318074ce2e

2. Shi W, Jin H, Li S, Liu M, Xie L: Indications of paediatric keratoplasty in north China . Clin Exp Ophthalmol. 2007, 35:724-727. 10.1111/j.1442-9071.2007.01618.x

3. Vanathi M, Panda A, Vengayil S, Chaudhuri Z, Dada T: Pediatric keratoplasty. Surv Ophthalmol. 2009, 54:245-271. 10.1016/j.survophthal.2008.12.011

4. Huang C, O'hara M, Mannis MJ: Primary pediatric keratoplasty: indications and outcomes. Cornea. 2009, 28:1003-1008. 10.1097/ICO.0b013e3181a186c0

5. Patel HY, Ormonde S, Brookes NH, Moffatt LS, McGhee CN: The indications and outcome of paediatric corneal transplantation in New Zealand: 1991-2003. Br J Ophthalmol. 2005, 89:404-408. 10.1136/bjo.2004.053116

6. Karadag R, Chan TC, Azari AA, Nagra PK, Hammersmith KM, Rapuano CJ: Survival of primary penetrating keratoplasty in children. Am J Ophthalmol. 2016, 171:95-100. 10.1016/j.ajo.2016.08.031

7. O’Hara MA, Mannis MJ: Pediatric penetrating keratoplasty. Int Ophthalmol Clin. 2013, 53:59-70. 10.1097/IIO.0b013e3182782a4b

8. Lekhanont K, Srikumaran D, Akpek EK: Pediatric keratoplasty. Expert Rev Ophthalmol. 2008, 3:655-663. 10.1586/17469899.3.6.655

9. Trief D, Marquezan MC, Rapuano CJ, Prescott CR: Pediatric corneal transplants. Curr Opin Ophthalmol. 2017, 28:477-484. 10.1097/ICU.0000000000000393

10. Low JR, Anshu A, Tan ACS, Htoon HM, Tan DT: The outcomes of primary pediatric keratoplasty in Singapore. Am J Ophthalmol. 2014, 158:496-502. 10.1016/j.ajo.2014.05.020

11. Kusumesh R, Vanathi M: Graft rejection in pediatric penetrating keratoplasty: clinical features and outcomes. Oman J Ophthalmol. 2015, 8:33-37. 10.4103/0974-620X.149862

12. Majander A, Kivelä TT, Krootila K: Indications and outcomes of keratoplasties in children during a 40-year period. Acta Ophthalmol. 2016, 94:618-624. 10.1111/aos.13040

13. Hovlykke M, Hjortdal J, Ehlers N, Nielsen K: Clinical results of 40 years of paediatric keratoplasty in a single 


\section{Cureus}

university eye clinic. Acta Ophthalmol. 2014, 92:370-377. 10.1111/aos.12198x

14. Limaiem R, Chebil A, Baba A, Ben Youssef N, Mghaieth F, El Matri L: Pediatric penetrating keratoplasty: indications and outcomes. Transplant Proc. 2011, 43:649-651. 10.1016/j.transproceed.2011.01.055

15. Al-Ghamdi A, Al-Rajhi A, Wagoner MD: Primary pediatric keratoplasty: indications, graft survival, and visual outcome. J AAPOS. 2007, 11:41-47. 10.1016/j.jaapos.2006.09.012

16. McClellan K, Lai T, Grigg J, Billson F: Penetrating keratoplasty in children: visual and graft outcome . Br J Ophthalmol. 2003, 87:1212-1214. 10.1136/bjo.87.10.1212

17. Dana MR, Moyes AL, Gomes JA, et al.: The indications for and outcome in pediatric keratoplasty: a multicenter study. Ophthalmology. 1995, 102:1129-1138. 10.1016/S0161-6420(95)30900-1

18. Stulting RD, Sumers KD, Cavanagh HD, Waring GO, Gammon JA: Penetrating keratoplasty in children . Ophthalmology. 1984, 91:1222-1230. 10.1016/S0161-6420(84)34171-9

19. Lowe MT, Keane MC, Coster DJ, Williams KA: The outcome of corneal transplantation in infants, children, and adolescents. Ophthalmology. 2011, 118:492-497. 10.1016/j.ophtha.2010.07.006

20. Chan AS, Colby K: Update on pediatric keratoplasty. Int Ophthalmol Clin. 2008, 48:25-33.

10.1097/IIO.0b013e3181694901 